\section{PREVENTIVE INOCULATION AGAINST INFLUENZA.}

To the Dditor of THE LANowT.

SIR,-I think that the official Memorandum on Prevention of Influenza just issued by the Medical Department of the Local Government Board casts an unmerited slur on the value of protective inoculation. I have had the opportunity of carrying out inoculation on a large scale and the results have been most satisfactory. Out of 1100 subjects about 800 were inoculated in November and December, and the figures at the end of January were as follows :-

\begin{tabular}{|c|c|}
\hline acidence among $\mathrm{i}$ & \\
\hline uses & 19 per cent. \\
\hline
\end{tabular}

Since the above date I have heard of another death among the non-inoculated.

In my opinion, inoculation can do no harm at the worst, almost certainly has a protective influence against infection, and certainly diminishes the risk of pulmonary complications. I am, Sir, yours faithfully,

Birchin-lane, E.C., Feb. 24th, 1919.

C. W. WIRGMAN.

\section{COMMERCIAL VACCINE LYMPHS.}

To the Editor of THE LANCET.

Sin,-My experience is very different from that of Mr. E. A Barton (THE LANCET, Feb. 22nd, p. 313). I was public vaccinator for 30 years and the payment depended upon results-viz., four successful vesicles. I found that the Local Government Board vaccine was not to be relied ufon, and I therefore always used Dr. Chaumier's lymph, with such good results that I received four vaccination grants during my period of office. In 1902 I vaccinated or revaccinated some 2000 , every one successful. Of course, I do not know the present virtue of the vaccine.

I am, Sir, yours faithfully,

Chelston, Devon, Feb. 22nd, 1919. A. T. ROWORTH.

\section{THE DISCUSSION ON SHOCK AT THE ROYAL SOCIETY OF MEDICINE.}

To the Editor of THE LANCET.

SiR,-In The LANCET report of the recent discussion on shock at the Royal Society of Medicine, from the variety of the opinions expressed, it is evident that there is, as yet, no general agreement in regard to the problem of the " missing blood." This problem is not solved by the assumptions of the speaker who stated that:-

"It is clear that blond must be accumulated or beld up somewhere or other in dilated regions of the vascular system. Observations made in the course of abdominal operations give no support to the view that there is any significant degree of dilatation of the arteries or veins of the splanchnic area. The region in question must therefore be that of the capillaries."

It is unsafe to assume that the missing blood must still be in some part of the vascular system, and it by no means follows that, because this blood is not in the splanchnic area, it must be in the capillaries. Very far from convincing is the same speaker's explanation of how blood can accumulate in capillaries without producing cyanosis.

"As regards the absence of marked cranosis in shock, we must remember that a very small dilatation of the capillaries, if widely distributed, may suck up a large volume of biood."

Scepticism is justifiable in regard to the clinical existence of an accumulation in the capillaries of blood sufficient in amount to be an important factor in shock and yet so widely distributed as to fail to cause cyanosis. Clinically the picture of shock is that drawn by Mr. John D. Malcolm-i.e., a contracted vascular system, a reduced capacity of the whole vascular area, and a diminution of the volume of blood in this area. The problem of the blood deficiency appears to be a question not so much of missing blood as of missing blood fluids, the total volume of the blood being diminished by the escape of blood fluids from the vascular system.

Might not laboratory workers, instead of looking for the missing blood in some part of a vascular system whose cubic capacity is greatly diminished, with advantage turn their attention to locating the missing blood fluids?

I am, Sir, yours faithfully,

Plymouth, Feb. 19th, 1919

C. HAMILTON WHITEFORD.

\section{Tle gegat and Gitter.}

\section{The Central Medical War Committee : THE} INTERESTS OF THOSE WHO HAVE BEEN

ON SERVICE.

THE steps which have been taken by the Central Medical War Committee for the members of the merlical profession who have been on service have been made the subject of a brief statement of the General Purposes Subcommittee. It may be remembered that Local Medical War Committees were instituted to protect the interests of medical men serving, to coöperate in the choice of those who should serve, and to provide for their medical work during their absence, the organisation areas of the British Medical Association being employed for the purpose. The Local Committees arranged a general agreement, under which half fees would be paid over by the practitioner remaining behind to the medical man on service, the patient to be handed back on return from service. Further, it was generally agreed that the substitute medical man should not attend the original patients of a medical man, who had been on service, for one year from the original doctor's return.

In two other directions was an attempt made to safeguard the position of those on service: regulations under the Insurance Act were made abrogating during the war the right of insured persons to change from the list of an absent doctor ; all Government Departments consented to approve the making of only temporary appointments during the war.

With regard to the position after demobilisation, a scheme was laid down which provided for priority on personal grounds, the primary consideration being length of service.

The statement continues as follows :-

In December last the Committee wrote to all the Government Departments which have medical work at their disposal urging that preference should, wherever possible, be given to doctors who have served. The Committee emphasised the need for this work being available during the first few months after the demobilised doctor's return, while he was building up his practice. The War Office, the Ministry of Pensions, the Ministry of National Service, and the Local Government Board all expressed their cordial agreement with this principle, and promised their support.

At the same time the L.M.W.C.s were informed of this step and were asked to help any man to secure such work who, on his return, expressed his desire for it. It was pointed out that vacancies should be made wherever necessary by the retirement of those who now hold the posts but who have done no service.

Any doctor who now returns and who wishes for local work of this kind should apply: (a) for military work to the D.D.M.S. of the Command, stating his service, and asking to be given any local work which may be available; $(b)$ to the secretary of the I.M.W.C. (name and address will be supplied on application) asking that the name of the applicant be placed on the list of those available for Pensions Boards or any similar work for which local practitioners are being employed.

So far as whole-time appointments are concerned, with the exception of an uncertain number which will be made by the Ministry of Pensions, the Committes knows of none except those connected with the local public health and education authorities. The latter are advertised in the medical journals, and the Central Government Departments concerned are being asked to press on the local authorities the necessity for stating that men who are on service may apply, though they have not yet been demobilised. Application should be made to the Ministry of Pensions for information about pensions medical appointments. Many applicants seem to be under the impression that the Ministry of National Service and the Ministry of Health have, or may shortly have, numbers of appointments of an administrative kind. There is no reason for this belief. The Ministry of National Service is shortly coming to an end, while the Ministry of Health is not yet in existence.

The experience of the Committee goes to show that doctors who return to civil life should have little difficulty in finding work, though it may be difficult for them to find just the kind of work they would prefer. Before the war the annual normal supply of doctors was hardly keeping pace with the demand, so there is little doubt that for some years to come there will be work for all. For five years the normal supply of fresh blood for the profession has been flowing into the services; consequently there are now many openings in all kinds of practice, but particularly, of course, in general practice. Moreover, during the years of the war 